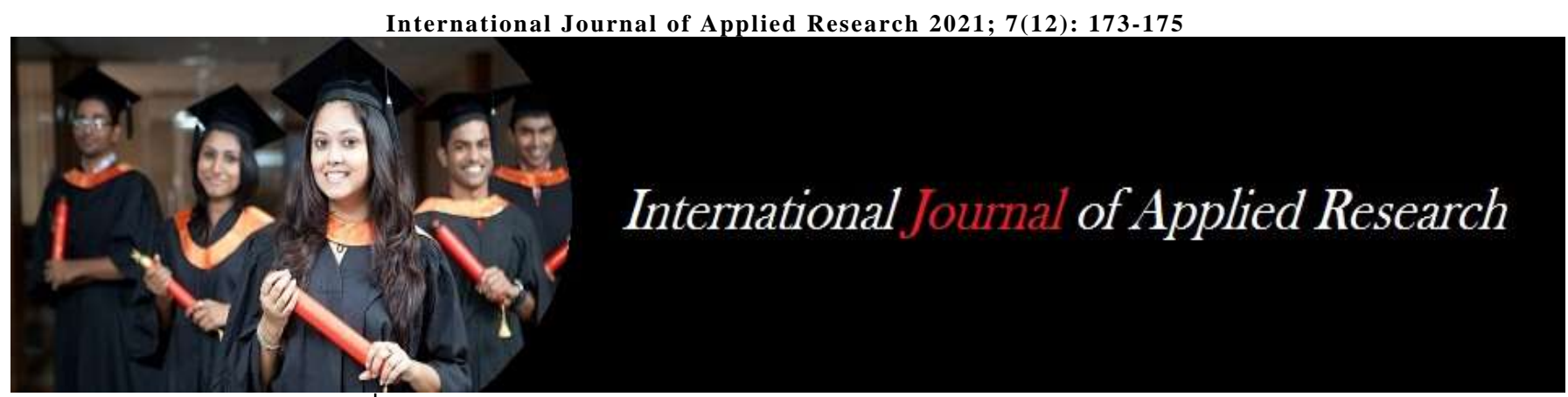

ISSN Print: 2394-7500

ISSN Online: 2394-5869

Impact Factor: 8.4

IJAR 2021; 7(12): 173-175

www.allresearchjournal.com

Received: 27-10-2021

Accepted: 30-11-2021

Dr. J Anusha Merline, Professor in Physiology, Dr. SM CSI Medical College \& Hospital, Karakonam, Thiruvananthapuram, Kerala, India

\section{Dr. S Babu Raj}

Professor in

Paediatrics, Department of

Paediatrics, Dr. SM CSI

Medical College \& Hospital,

Karakonam,

Thiruvananthapuram, Kerala, India

\section{Ajitha Jothis ST}

Associate Professor, CSI

College of Nursing, Dr. SM CSI

Medical College \& Hospital,

Karakonam, Thiruvananthapu

ram, Kerala, India
Corresponding Author: Dr. J Anusha Merline, Professor in Physiology, Dr. SM CSI Medical College \& Hospital, Karakonam, Thiruvananthapuram, Kerala, India

\section{Alterations in physiological parameters in childhood obesity}

\author{
Dr. J Anusha Merline, Dr. S Babu Raj and Ajitha Jothis ST
}

DOI: $\underline{\text { https://doi.org/10.22271/allresearch.2021.v7.i12c.9240 }}$

\section{Abstract}

Background: The changing lifestyle and the improved economical status have increased the prevalence of obesity among children. Since child hood obesity leads is a forerunner of obesity in adulthood, this study was aimed to assess the changes in the anthropometric and biochemical parameters in childhood obesity.

Methodology: A cross sectional study was conducted among the children studying in the public schools which cater to the affluent segment of the population in South India. A total of 75 school children studying in $5^{\text {th }}, 6^{\text {th }}$ and $7^{\text {th }}$ standards in the age group of 9-12 years, who were apparently obese, were selected. The data collection was done after obtaining the informed written concern from the Head-mistress, the parents and assent from the students. The data analysis was done.

Results: It was found that the anthropometric measurements, blood pressure and lipid profile was significantly higher in obese children $(P<0.001)$.

Conclusion: Thus this study has proved that obesity leads to metabolic derangements and morbidity. Proper screening and health education of children and parents can prevent onset lifestyle diseases and their complications.

Keywords: Physiological parameters, childhood obesity, economical status

\section{Introduction}

India, a country with a billion people is in a state of dynamic, economic and health transformation. The fast industrialization results in rapid urbanization and economic growth. Hence, in the modern society, with the improved economic status and changing life style in the urban population, we come across increasing prevalence of obesity especially among children. Childhood obesity has a tracking correlation to the obesity in adulthood. We are aware that obesity either results in or is associated with the dieses like Diabetes Mellitus, Hypertension, Cardio Vascular disorders and psychological setbacks ${ }^{[1]}$. This study is undertaken to find the alterations in the various physiological parameters in obese school children.

\section{Aim of the study}

To assess the changes in the anthropometric and biochemical parameters in childhood obesity.

\section{Methodology}

The cross sectional study was conducted among the children studying in the public schools which cater to the affluent segment of the population in South India after obtaining consent from the school Head-mistress, the parents and assent from the students. A total of 75 school children studying in $5^{\text {th }}, 6^{\text {th }}$ and $7^{\text {th }}$ standards in the age group of 9-12 years, who were apparently obese, were selected.

The standing height and weight were measured in them using stadiometer and standard weighing machine. BMI was calculated in these children and 50 of them were found to be obese (Group I - Boys 26; Girls 24) ${ }^{[2]}$. The other causes of obesity were excluded after obtaining the relevant history (regarding treatment) and gross physical examination. Childhood obesity has been determined after considering the standard for BMI at or above the 85 percentile for age and sex ${ }^{[3]}$. 
Thus the two groups - one group (Group I) of 50 obese children and another group (Group II) of 25 control children have been selected for our study.

The circumference of the waist was measured at the level of the umbilicus. The circumference of the hip was measured as the widest part of the gluteal region. ${ }^{[4]}$ Both the measurements were measured using measuring tape in both control and obese children.

The Triceps skin fold thickness was measured using Harpenden's skin fold Calipers following the standard procedure described by Owen GM. This consists of measurement of a double layer of skin and subcutaneous fat on the dorsal aspect of the arm halfway between the tip of the acromium process of the scapula and the olecranon process of the ulna with the arm hanging by the side of the trunk ${ }^{[5]}$. A skin fold parallel to the long axis of the arm and including the subcutaneous fat was pulled away from the underlying tissue $1 \mathrm{~cm}$ above the site at which the calipers were used to determine the thickness to the nearest $\mathrm{mm}$. The reading was taken 2 to 3 seconds after the jaws of the calipers have been exerted. The procedure was repeated three times and the average of the measurements was recorded.

Lipid profile including the Total Cholesterol, Triglycerides, LDL, and HDL has been estimated in the Biochemistry laboratory by enzymatic colorimeter meter method in the fasting state.

\section{Results}

Table 1: Comparison of anthropometric measurements of control and obese children

\begin{tabular}{|c|c|c|c|c|c|c|c|c|c|}
\hline & \multicolumn{2}{|c|}{ Age in Years } & \multicolumn{2}{c|}{ Height in cm } & \multicolumn{2}{c|}{ Weight in Kg } & \multicolumn{2}{c|}{ BMI } & \\
\cline { 2 - 9 } & Control & Obese & Control & Obese & Control & Obese & Control & Obese & \multirow{2}{*}{$P<0.01$} \\
\hline Mean & 11.44 & 11.18 & 141.28 & 147.26 & 36.4 & 56.38 & 18.08 & 25.94 & \\
$\sigma$ & 0.5831 & 1.0039 & 7.7595 & 9.2622 & 6.5256 & 10.2577 & 1.6945 & 2.0201 & \\
\hline
\end{tabular}

Table 2: Comparison of Skin fold thickness, Hip Circumference and Waist Circumference of control and obese children.

\begin{tabular}{|c|c|c|c|c|c|c|c|}
\hline & \multicolumn{2}{|c|}{ SFT in mm } & \multicolumn{2}{c|}{ Waist Circumference in cm } & \multicolumn{2}{c|}{ Hip Circumference in cm } & \\
\cline { 2 - 7 } & Control & Obese & Control & Obese & Control & Obese & \multirow{2}{*}{$P<0.01$} \\
\hline Mean & 16.72 & 27.18 & 71.87 & 81.4 & 81.75 & 92.9 & \\
$\sigma$ & 1.41 & 4.1105 & 6.4115 & 7.7563 & 6.565 & 7.9195 & \\
\hline
\end{tabular}

On comparison of the anthropometric measurements of obese and control children, we found that

1. The BMI of the obese children is higher than that of control children and the increase is statistically highly significant.
2. The Triceps skin fold thickness of the obese children is higher than that of the control children and the difference is statistically highly significant.

3. The Waist and hip Circumference in $\mathrm{cm}$ is found to be more in obese children than those in control group and the difference is statistically highly significant.

Table 3: Comparison of blood pressure in control and obese children

\begin{tabular}{|c|c|c|c|c|c|c|}
\hline & \multicolumn{2}{|c|}{ Systolic Pressure in $\mathbf{m m}$ of $\mathbf{H g}$} & \multicolumn{2}{|c|}{ Diastolic Pressure in $\mathbf{~ m m}$ of $\mathbf{H g}$} \\
\cline { 2 - 3 } & Control & Obese & \multirow{2}{*}{$\boldsymbol{P}<\mathbf{0 . 0 1}$} & Control & Obese & \multirow{2}{*}{$P<0.01$} \\
\cline { 5 - 6 } & 97.28 & 111.76 & 70.64 & 75.32 & \\
\hline Mean & 8.9234 & 10.7562 & & 7.3648 & 7.2689 & \\
\hline
\end{tabular}

Both systolic and diastolic blood pressure in the obese children are found to be increased as compared to those of the control children and found to be statistically highly significant.

Table 4: Comparison of fasting lipid profile in control and obese children

\begin{tabular}{|c|c|c|c|c|c|c|c|c|}
\hline & $\begin{array}{c}\text { Cholesterol in } \\
\text { mg\% }\end{array}$ & \multicolumn{2}{|c|}{ LDL in mg\% } & \multicolumn{3}{c|}{ HDL in mg\% } \\
\cline { 2 - 5 } & Control & Obese & Control & Obese & \multirow{2}{*}{ Control Obese } & \\
\hline Mean & 167.32 & 178.28 & 87.24 & 117.7 & $P<$ & 37.28 & 24.02 & $P<$ \\
$\sigma$ & 15.0491 & 31.3616 & 17.7060 & 35.2781 & 0.01 & 2.9229 & 12.2302 & 0.01 \\
\hline
\end{tabular}

The serum cholesterol level is found to be raised in obese children, when compared to the value found in control group, but not statistically significant.

The HDL cholesterol level is found to be lower in obese children as compared with that of control children and found to be statistically highly significant.
The LDL level in the obese children is higher when compared to the LDL level in control children. This difference is found to be statistically highly significant.

\section{Statistical analysis}

Student " $t$ " test

Statistical analysis was done using the " $t$ " test. The significance was done drawn at $\mathrm{P}$ (probability) of 0.001 . 0.01 and 0.05 . This means that the results are valid to the extent of $99.9 \%, 99 \%, 95 \%$ respectively.

Table 5: Anthropometrical Statistical Analysis

\begin{tabular}{|c|c|c|c|c|}
\hline & BMI & SFT mm & Waist cm & Hip cm \\
\hline Obese children X & $* * *$ & **** & **** & **** \\
\hline Control children & 0.0000107 & 0.000001 & 0.000001 & 0.0000001 \\
\hline Obese boys X & $* * *$ & *** & *** & ** \\
\hline Control boys & 0.0000003 & 0.000009 & 0.0018 & 0.00157 \\
\hline Obese girls X & **** & $* * *$ & $* * *$ & $* * *$ \\
\hline Control girls & 0.00001 & 0.000135 & 0.0001 & 0.00016 \\
\hline
\end{tabular}


Table 6: Biochemical Statistical Analysis

\begin{tabular}{|c|c|c|c|}
\hline & HDL mg\% & LDL mg\% & Cholesterol mg\% \\
\hline $\begin{array}{c}\text { Obese children X } \\
\text { Control children }\end{array}$ & $\begin{array}{c}* * * \\
0.000089\end{array}$ & $\begin{array}{c}* * * \\
0.000041\end{array}$ & 0.4448 \\
\hline $\begin{array}{c}\text { Obese boys X } \\
\text { Control boys }\end{array}$ & $\begin{array}{c}* * * \\
0.0002\end{array}$ & 0.05 & 0.905 \\
\hline $\begin{array}{c}\text { Obese girls X } \\
\text { Control girls }\end{array}$ & $\begin{array}{c}* * * \\
0.001\end{array}$ & 0.2234 & 0.938 \\
\hline
\end{tabular}

*** $P<0.001$ Very Highly Significant

** $P<0.01$ highly significant

\section{Discussion}

The height, weight waist circumference, hip circumference and the triceps skin fold thickness are found to be significantly increased in obese children compared with the control group. The causative factors vary from the genetic constitution to the behavioral pattern alterations among the obese children, 17 of them had the family history of parents suffering from diabetes mellitus either in one (or) both of them. This might contribute for the development of obesity in childhood. This finding coincides with the earlier study done by Bouchard et al. (1990) ${ }^{[6]}$. Compared with control, children in the obese group had statistically significant increase in systolic blood pressure and diastolic blood pressure. This finding is consistent with the previous study done by Moussa-MA et al., on the obese school children of United Arab Emirates in September 1992-1993 ${ }^{[7]}$.

The increase in blood pressure occurs due to the sympathetic nervous activity. The insulin level is increased whenever there is absorption of products of digestion. The psychological factors, when the obese children compare themselves with the peer group cause anxiety, which also can contribute to the catecholamine and glucocorticoid secretion, which in turn might cause an increase in blood pressure.

Regarding the study of lipid profile in obese and control children, the following facts are revealed - (1) The total cholesterol level and LDL level are found to be increased in obese compared to the control children (2) The HDL cholesterol level is found to be significantly lowered in obese children compared to the control children. These findings correlate well with the previous studies done by Patrick Tounian et al. in $2001^{[8]}$ on obese children in France and Indian population by Dr N. K. Anand et al. in $2000^{[9]}$. The obese girls had higher mean total cholesterol levels and LDL levels compared to obese boys. This may be associated with the increase in adipose tissue and overall weight gain during the pubertal growth spurt, as reported by the NHANES data.It has been shown that each risk factor separately increases the risk of Coronary Artery Disease five to ten times when compared with persons having no risk factors. In this study 36 of the 50 obese children gave family history of Hypertension and Diabetes mellitus either in one or both parents. This finding is consistent with the findings of the Montreal Adoption study (1986) which pointed out that there are genetic influences on the level of blood pressures in children ${ }^{[9]}$. Widgren et al., 1982 have shown that young normotensive humans with a positive family history of hypertension have significantly elevated body weight compared with those with negative family history [10].

\section{Conclusion}

Thus this study has shown substantial evidence that obesity in childhood lays the metabolic groundwork for adult cardiovascular disease, diabetes mellitus. It is therefore highly recommended to do baseline Biophysical profile and anthropometric measurements in suspected obese children during early adolescence to prevent life style diseases in the future. Proper health education and physical activity during childhood will prevent metabolic derangements and improve psychological wellbeing in children. Thus the health of the society on the whole improves and the burden on the health care system of the country is minimized.

\section{References}

1. Krushnapriya Sahoo, Bishnupriya Sahoo Childhood obesity: causes and consequences J Family Med Prim Care 2015;4(2):187-192.

2. Fryar $\mathrm{CD}, \mathrm{Gu} \mathrm{Q}$, Ogden CL, Flegal KM. Anthropometric Reference Data for Children and Adults: United States, 2011-2014. Vital Health Stat 2016;3(39):1-46.

3. Neslihan Koyuncuoglu Gungor Overweight and Obesity in Children and Adolescents Journal of Clinical Research in Pediatric Endocrinology 2014;6(3):129 143

4. Wang J, Thornton JC, Bari S et al. Comparisons of waist circumferences measured at 4 sites. Am J Clin Nutr 2003;77:379-384.

5. Indian Academy of Pediatrics Growth Charts Committee, Khadilkar V, Yadav S, Agrawal KK, Tamboli S, Banerjee M, Cherian A et al. Revised IAP growth charts for height, weight and body mass index for 5- to 18-year-old Indian Children. Indian Pediatr 2015;52:47-55.

6. Claude Bouchard, George Bray A, Van S. Hubbard Basic and clinical aspects of regional fat distribution American Journal for Clinical Nutrition 1990;52:94650.

7. Al-Haddad F, Al-Nuaimi Y, Little BB, Thabit M. Prevalence of obesity among school children in the United Arab Emirates. American Journal of Human Biology: The Official Journal of the Human Biology Association 2000;12(4):498-502.

8. Tounian P, Aggoun Y, Dubern B, Varille V, GuyGrand B, Sidi D. Presence of increased stiffness of the common carotid artery and endothelial dysfunction in severely obese children: a prospective study. The Lancet 2001;358(9291):1400-4.

9. Anand NK, Carreira EM. A simple, mild, catalytic, enantioselective addition of terminal acetylenes to aldehydes. Journal of the American Chemical Society 2001;123(39):9687-8.

10. Widgren S, Cox JN. Muscular abnormalities of the small intestine. Their possible role in ischemic lesions of the intestine. Schweizerische medizinische Wochenschrift 1982;112(44):1540-4 